\title{
Os Troncos Missioneiros e a construção da identidade missioneira a partir da música
}

\author{
Iuri Daniel Barbosa
}

Mestrando do Programa de Pós-Graduação em Geografia da UFRGS. E-mail: iuribar@yahoo.com.br

Recebido em 04/2012. Aceito para publicação em 12/2012.

Versão online publicada em 01/02/2013 (http://seer.ufrgs.br/paraonde)

\begin{abstract}
Resumo: Troncos Missioneiros é o nome de um disco que reúne quatro artistas da Região Missioneira do Rio Grande do Sul: Jaime Caetano Braun, Noel Guarany, Cenair Maicá e Pedro Ortaça. Além de fomentar uma Música Regional Missioneira, o principal legado dos artistas relacionados como "Troncos Missioneiros" está no pioneirismo da construção de uma identidade missioneira através da música. No que tange a identidade regional, são enfatizados algumas temáticas principais: as características de um passado rural; a fronteira de integração latino-americana; as Reduções Guaraníticas e suas ruínas. Já a construção de uma Música Regional Missioneira, parte de algumas influências anteriores importantes, mas é consolidada pelos artistas citados. Depois deles, há um grande leque de artistas nascidos na região que se identificam com a produção musical missioneira, vários destes parentes diretos dos Troncos. Num contexto maior, a partir dos anos 90, a música regional do Rio Grande do Sul se desenvolve por dois caminhos: Música Campeira e a Tchê Music. Em ambos, há regravações da obra musical dos Troncos Missioneiros. Com o objetivo de discutir esse tema, utilizamos como metodologia a pesquisa em arquivos sonoros no Museu do Som Regional do RS, localizado junto ao Instituto Gaúcho de Tradição e Folclore (IGTF) e também do acervo de discos que encontramos na internet. Nosso trabalho vincula-se a uma Geografia Cultural Renovada, a partir da inclusão de novos objetos de estudo, em nosso caso a música.
\end{abstract}

Palavras-chave: Música e Geografia. Música Regional. Identidade Missioneira.

"São quatro cernos de angico Falquejados na minguante, ue vêm trazendo por diante

Nosso tesouro mais rico,

Que há três séculos e pico

Os centauros nos legaram

Memórias que não gastaram Nos entreveiros da infância;

E olfateando na distancia,

Algumas que se extraviaram.

Os quatro são missioneiros,

Unidos num mesmo abraço;

São tentos do mesmo laço,

Brasas dos mesmos braseiros,

Chispas dos mesmos luzeiros,

Que onde um vai o outro vai.

Nenhum pesar os contrai

Nem desencanto nem mágoa;

Os quatro beberam água

Nos remansos do Uruguai."

(BRAUN, 1987)

\section{Introdução}

Nosso trabalho vincula-se a uma Geografia Cultural Renovada, a partir da inclusão de novos objetos de estudo, como também de novas abordagens a objetos que já eram de interesse, onde os estudos geográficos sobre música exemplificam essa situação (CASTRO, 2009, p. 7). "Dessa forma, compreendemos a música como um texto, um "espaço multi-dimensional”, aberto, fragmentário, inacabado e incoerente, receptivo a múltiplas interpretações concorrentes" (KONG, 2007, p. 155).

Muitas vezes, o "caráter e a identidade dos lugares são apreendidos a partir de letras, melodia, instrumentação e da "percepção" geral ou do impacto sensorial da música (KONG. 2007, p. 137)". Desse modo, os estudos que relacionam Música e Geografia "oferecem ricas evocações de lugares, de uma forma geralmente ausente nas fontes geográficas convencionais" (KONG. 2007, p. 137).

Troncos Missioneiros é o nome de um disco (um LP lançado em vinil em 1988 e re-lançado em CD na década de 2000) que reúne quatro artistas da Região Missioneira do Rio Grande do Sul: Jaime Caetano Braun, Noel Guarany, Cenair Maicá e Pedro 
Ortaça. Com registros fonográficos a partir dos anos 1970, a obra desses artistas está intimamente relacionada à construção da identidade missioneira no Rio Grande do Sul, Brasil. Também podem ser considerados como troncos de uma "Música Regional Missioneira", que acabou por influenciar uma parcela significativa da música regional produzida nesse estado.

\section{Os quatro Troncos Missioneiros}

Em uma árvore, um tronco é um tipo de caule lenhoso, resistente, cilíndrico ou cônico. Já em anatomia, tronco é a parte central, de onde se projetam a cabeça e os membros. Fazendo analogia com nossos artistas, podemos dizer que Jayme, Noel, Ortaça e Cenair são a base, de onde se projetará a Música Regional Missioneira. Como Jayme os define, são quatro cernos de angico. Ainda nos anos 60, os quatro artistas se reuniram, objetivados a colocar o território missioneiro no mapa musical gaúcho. Conforme as palavras de Pedro Ortaça (2011):

Em meados de 1966 eu, juntamente com Noel Guarani e Cenair Maicá nos reunimos para tocar e cantar e decidimos que iríamos criar um novo modo de tocar e cantar. A maneira que as coisas do Rio Grande eram colocadas não nos satisfaziam, não era a maneira que queríamos para o norte do nosso trabalho. Nos reunimos para tocar e cantar a identidade musical missioneira.

Além dos três artistas citados no trecho acima, Ortaça faz referência a outro missioneiro, Jayme Caetano Braun. "que nos serviu de fonte e vertente para o nosso trabalho" (ORTAÇA, 2011).

Jayme Caetano Braun nasceu no distrito da Timbaúva, interior do município de Bossoroca ${ }^{2}$, em 1924. Afirmava ser neto de índia guarani, chegou a ser tropeiro e curandeiro, também trabalhando em profissões urbanas, como radialista, jornalista e funcionário público. Braun morreu em Porto Alegre, em 1999. É considerado o difusor da Payada (poesia declamada, de origem platina) no Brasil. Jaime Caetano Braun lançou nove livros de poesia, além de dez discos contendo payadas e músicas instrumentais. Teve poesias musicadas por inúmeros artistas, entre eles Noel Guarany, Cenair Maicá, Pedro Ortaça e Luís Marenco.

Também de Bossoroca é Noel Guarany, nascido em 1941 (faleceu em Santa Maria, em 1998). Descendente de guaranis e italianos. Trabalhou como balseiro, lenhador, tarefeiro de mate e também foi radialista. Ainda na juventude, percorre os países do Prata, recolhendo canções que chamaria de "Cancioneiro Guaranítico" ${ }^{3}$ (SOSA, 2003, p. 25). A esse trabalho, qualifica como "Música de pesquisa", contrapondo-se aos Festivais de Música Nativista, dos quais não participava (POMMER, 2009, p. 175). A ele é creditada, por Pommer (Ibid., p. 173174), a tarefa de divulgação e o reconhecimento da região como missioneira por seus habitantes. Conforme depoimento do próprio autor, quando afirma que "na época que eu comecei a cantar não existia música missioneira e eu me vi na obrigação de cantar e a música missioneira está aí" (MANN, 2002, p. 8).

No fim dos anos 70, passa a ter reconhecimento da intelectualidade. Apresenta-se em universidades públicas tornando-se conhecido do público estudantil. Em 77 foi convidado a participar de evento no centro do país, juntamente com Edu Lobo, Chico Buarque, entre outros artistas da MPB. Por seu conteúdo crítico, o show acabou cancelado pelo governo ditatorial daquele período. Passa a ter expressão em jornais do centro do país, através de matérias escrita. Por conta das reportagens, divulga São Luiz Gonzaga, que começa a ficar conhecida como capital da música missioneira (POMMER, 2009, p. 176-177).

Também nascido em Bossoroca, em 1942, Pedro Ortaça aprendeu a tocar com os pais, que eram músicos de "bailantas" no interior. Em 2008 recebeu o título, pelo Ministério da Cultura, de Mestre da Cultura Popular Brasileira (BRASIL, 2008). Para Ortaça (2011), "a diferença da música missioneira para a produzida em outras regiões do Estado está na maneira de cantar-denunciando, protestando, registrando e levando para o futuro o passado de um povo esquecido, explorado, mas cheio de encanto e essências, o povo Guarani." Em outro depoimento, Ortaça enfatiza a importância dos "Troncos Missioneiros" para a representação histórica da região:

Através do nosso canto, o povo foi conhecendo a verdadeira história do povo missioneiro, povo de quem foram roubadas as terras, o gado, as riquezas. Mataram, velhos, moços e crianças num extermínio bárbaro. Mas não conseguiram silenciar a voz da verdade, que era ouvida e esparramada pelo vento de coxilha em coxilha, como se fosse um lamento. Não conseguiram apagar sua história de lutas, fraternidade e amor a esse chão colorado! (ORTAÇA apud JÚDICE, 2009)

Missioneiro, do município de Tucunduva, Cenair Maicá nasceu em 1947. Aos três anos, cruzou a fronteira com sua família para viver em acampamentos de extração de madeira às margens do Uruguai. Criado em meio aos madeireiros, balsei- 
ros e pescadores, absorveu desde cedo à musicalidade de suas formas de expressão: foi com os peões argentinos e paraguaios que trabalhavam com seu pai que aprendeu os primeiros acordes da guitarra. Morreu em Porto Alegre em janeiro de 1989 (MANN, 2002, p. 12-13).

Suas canções falam da natureza (rios, matas, pássaros, diversidade), retratam os problemas urbanos: o favelado, o louco, os índios marginalizados, os sem terra, o campo devastado (monocultura, poluição). Além de cantar a história e a identidade missioneira, apresentava-se como um artista engajado, valorizando o sentido e a utilidade ao povo no seu cantar. Nesse depoimento, Cenair fica mais claro:

Eu tenho me dedicado a cantar não só a história que passou, os costumes, mas a realidade do homem da minha região. Eu acho que o músico além de cantar as coisa alegres, a paisagem, a história, tem o dever de ser útil ao povo com o qual convive no dia-a-dia. Então eu procuro, dentro da minha música, dizer alguma coisa que possa motivar ou sensibilizar pessoas no sentido de resolver certos problemas de nosso povo. Porque nós, os artistas, temos uma força na mão, que é o instrumento, e temos a oportunidade de nos comunicar com o povo através dos canais de divulgação. Então temos o dever de ser útil ao povo. Nossa luta não pode ser com armas, mas através da palavra (MANN, 2002, p. 16).

\section{Identidade Missioneira a partir dos Troncos Missioneiros}

Acreditamos que "os textos musicais devem ser entendidos como diálogos sociais em andamento, os quais ocorrem em determinadas situações sociais e históricas e refletem esses cenários" (KONG, 2007.139-140). Nesse sentido, a obra musical dos Troncos Missioneiros pode ser contextualizada no bojo das transformações que a região das Missões passava. Nos anos 1960 ganha força o processo de modernização do campo na região, através da substituição da pecuária e lavoura tradicional pela agricultura de grãos ${ }^{4}$. Neste período foi grande o êxodo rural, sendo que os Troncos Missio- neiros vivenciaram esse processo: nasceram no campo e migraram para as cidades. Essa transformação do rural não passou despercebida pelos artistas, gerando nostalgia de um passado idealizado, de forma análoga a outros trabalhos que relacionam Música Popular e Geografia, conforme pontua Kong (2007, p. 140), "como uma consequência, a paisagem rural e o estilo de vida agrário do passado são idealizados, principalmente entre migrantes desarraigados. Há uma saudade de casa e a nostalgia amarga de um modo de vida que parece ter sido irremediavelmente perdido, e o passado enevoado passa a ser reavaliado como um lugar sagrado."

A situação geográfica da região missioneira, fronteira do Brasil com a Argentina e nas proximidades do Paraguai, transparece como elemento identitário. Nas letras das canções e payadas é frequente a ideia de integração latino-americana, de união entre os países irmãos. Para isso, é utilizado como referência o território histórico dos Guaranis reunindo partes de Brasil, Argentina, Paraguai, Uruguai. A fronteira também efetivou um maior contato entre os Troncos Missioneiros com elementos da música platina. Assim, houve intercâmbio musical com os artistas Argentinos Chaloy Jara, Raulito Barboza ${ }^{1}$, Lúcio Yanel ${ }^{2}$, Talo Pereira, Mártin Coplas. Além disso, foram regravados temas e canções de compositores como Atahualpa Yupanqui ${ }^{3}$, Transito Cocomarola, Anibal Sampayo. Como também de ritmos platinos como o chamamé, a guarânia, a milonga, o rasguido doble e rancheira (OLIVEIRA \& VERONA, 2008).

Entendemos que a análise das letras não corresponde a totalidade para a compreensão de significados. Por isso, outros materiais intertextuais devem ser incluídos como os visuais, uma vez que também comunicam significados e falam de identidades que as pessoas desejam desenvolver e apresentar. (KONG, pág. 158). Na formação dessa identidade missioneira articulada pelo grupo, algumas imagens expressam evidência disso. É o caso da imagem das Ruínas de São Miguel ${ }^{4}$ como pode ser visto nas figuras 1 e 3 , considerada a iconografia mais forte da região missioneira, presente nos discos dos Troncos Missioneiros, como também de inúmeros outros artistas identificados com a região. Outras iconografias bastante presentes são o Rio Uruguai (FIG. 2) e a Cruz Missioneira (foto 4).

\footnotetext{
${ }^{1}$ Natural de Buenos Aires, participou das gravações de Pajador, Pampa e Guitarra de Noel Guarany. Atualmente mora em Paris, sendo um dos principais nomes vivos do Folclore Argentino.

${ }^{2}$ Violonista, nascido em Corrientes, que gravou com Jaime Caetano Braun, Cenair Maicá e Pedro Ortaça. Radicado no Rio Grande do Sul desde 1982 é o considerado o mais importante violonista da Música Regional do RS.

${ }^{3}$ Natural de Buenos Aires, é considerado um dos mais importantes divulgadores da Música Folcórica Argentina.

${ }^{4}$ Sítio arqueológico localizado na cidade de São Miguel das Missões o mais preservado de todos os situados em território brasileiro.
} 
1

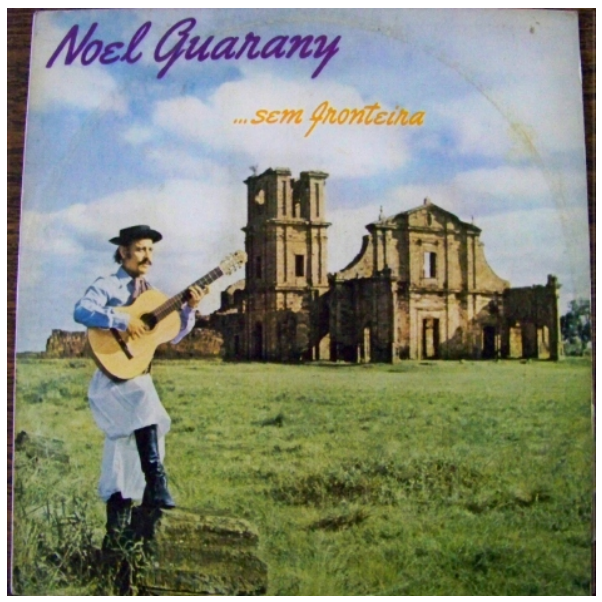

3

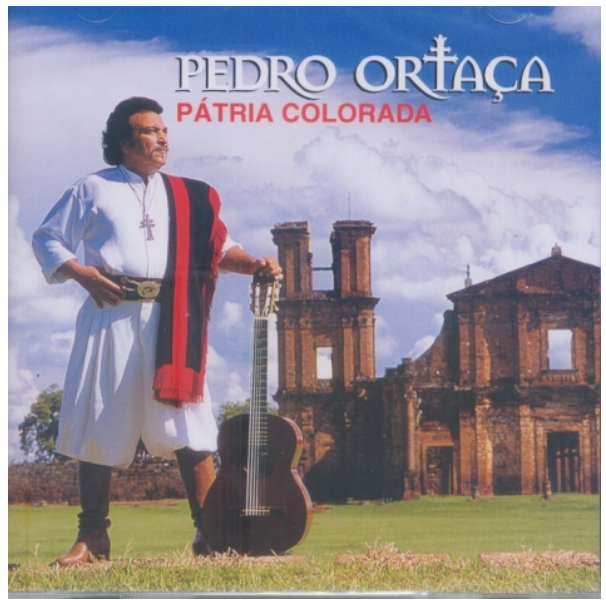

2

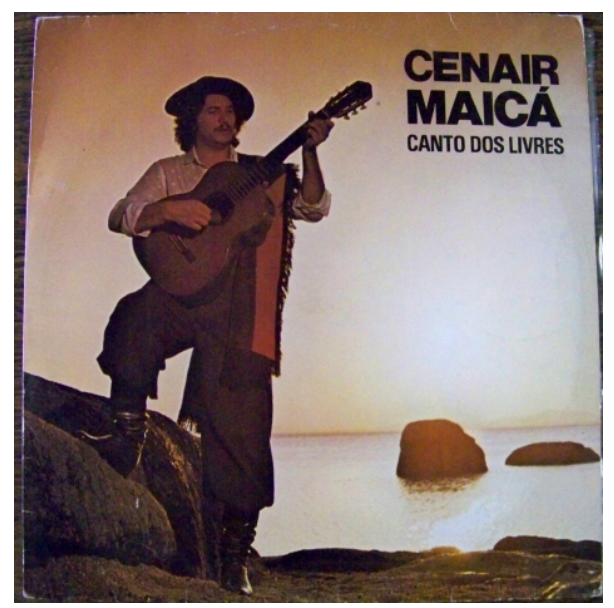

4

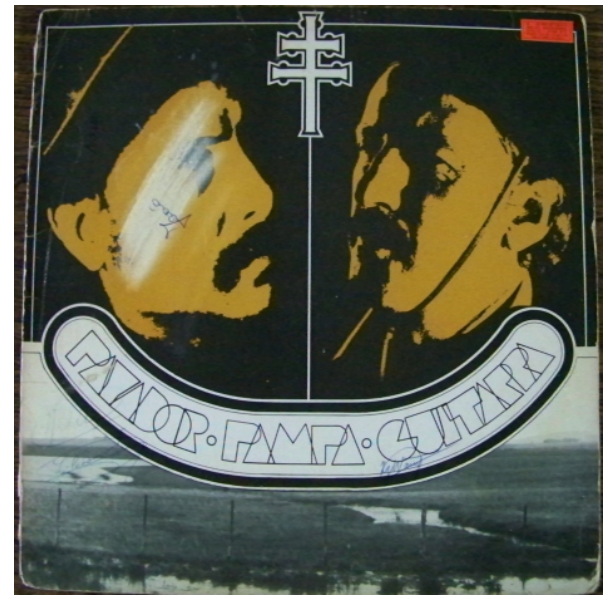

Figs 1-4. 1 - Capa do disco Sem Fronteira, de Noel Guarany, 1975. 2 - Capa do disco Canto dos Livres, de Cenair Maicá, 1983. 3 - Capa do disco Pátria Colorada, de Pedro Ortaça, 2007. 4 - Capa do disco Payador, pampa e guitarra, de Noel Guarany e Jayme Catano Braun, 1976.

\section{Música Regional Missioneira}

Segundo Brum (2005, p. 124), o termo Música Missioneira compreende dois significados distintos: no primeiro - histórico -, é uma música executada nos Sete Povos, ensinada pelos padres jesuítas, reproduzida e (re)inventada pelos índios Guaranis; já no segundo - atual -, a Música Missioneira refere-se ao regionalismo, feita como possibilidade de nomeação e de classificação do passado missioneiro no presente, no sentido de apologizá-lo para revivê-lo. Chamaremos esta de Música Regional Missioneira, na qual possui grande importância os artistas referidos ao qual nos referimos como Troncos Missioneiros. Segundo Pommer (2009, p. 164) as características principais desta Música Regional Missioneira, produto da cultura específica de uma parte da região das Missões eram a denúncia e o protesto. Aindaegundo a autora, a música dos Tron- cos Missioneiros pode ser compreendida como a recriação de um passado específico, procurando conectá-lo ao presente. Esse passado esta relacionado ao período das Reduções Jesuíticas dos índios Guaranis.

Os Troncos Missioneiros possuem grande importância na construção de uma Música Regional Missioneira. Podemos dizer que esses artistas foram o cerne, como bem sugere analogia ao tronco de uma árvore, de onde partiram as ramificações que preservam, reconstroem e atualizam a identidade musical missioneira. A construção de uma Música Regional Missioneira parte de algumas influências anteriores importantes, como raízes que deram sustentação aos cernes, como Reduzino Malaquias $^{5}$ e Tio Bilia ${ }^{6}$. Seguindo a linhagem dos "Troncos Missioneiros", brotam hoje novos galhos, alguns deles seus descendentes e parentes diretos: os irmãos Alberto, Gabriel e Marianita Ortaça ${ }^{7}$; Val-

${ }^{5}$ Gaiteiro, nascido no interior de São Nicolau, gravou os primeiros discos de Pedro Ortaça, além de um disco solo instrumental, no fim da vida.

${ }^{6}$ Expoente da gaita ponto, nascido em Santo Ângelo

${ }^{7}$ Filhos de Pedro Ortaça, comumente se apresentam junto ao pai, formando a Família Ortaça. 
domiro Maicá ${ }^{8}$ e seu filho Atahualpa, Patrício Maicá ${ }^{9}$ e por fim, Laura Guarany ${ }^{10}$.

Além dos familiares, outros artistas também se identificam como missioneiros, mesmo que abrangendo outras temáticas e propostas estéticas musicais. Em uma vertente mais relacionada a uma música de protesto, está Jorge Guedes e seus filhos Anaí e Karay Guedes ${ }^{11}$. Noutra, mais ligada ao nativismo $^{12}$, tem como expoentes os músicos Luiz Carlos Borges ${ }^{13}$, Érlon Péricles ${ }^{14}$ e Ângelo Franco ${ }^{15}$. Também há uma ramificação mais "popularesca", inspirada em trovadores, geralmente associada a temáticas irônicas ou letras de duplo sentido, onde os expoentes são Xirú Missioneiro ${ }^{16} \mathrm{e} \mathrm{Baitaca}^{17}$.

Devemos ressaltar a influência dos Troncos Missioneiros na Música Popular do Rio Grande do Sul, como também em outros estados brasileiros e em países vizinhos. A partir dos anos 90, a música regional do Rio Grande do Sul se desenvolve, conforme DIAS (2008, p. 52), por dois caminhos: a Música Campeira, onde prevalecem os artistas do Sul do RS, e a Tchê Music, mais enraizada no Norte do RS e em outros estados brasileiros. Em ambas linhas, há regravações da obra musical dos Troncos Missioneiros. Na Música Campeira, onde prevalece o uso de violão, gaita e contrabaixo (às vezes acrescido de percussão), onde o grande expoente é Luiz Marenco. Marenco gravou um disco só com canções de Noel Guarany ("Luís Marenco canta Noel Guarany", de 1996) e outro musicando letras de Jaime Caetano Braun, intitulado "Luís Marenco canta Jaime Caetano Braun", de 1991. Além disso, durante sua carreira, regravou a canção Mágoas de Posteiro, de autoria de Cenair Maicá, no disco "Filosofia de Andejo" de 1993. Também na música campeira, a dupla: César Oliveira \& Rogério Mello, fãs de Pedro Ortaça, homenageiam o missioneiro com o título de um tema instrumental no disco "Cantigas para o meu chão", de 2010. Por sua vez, o artista Juliano Amaral chega a apresentar um espetáculo somente com canções de Noel Guarany e Cenair Maicá (PROSA GALPONEIRA, 2010).

Nas bandas de Tchê Music e nos conjuntos de baile também há referência aos Troncos Missioneiros. Embora não seja tão presente como na música campeira, há várias regravações por alguns dos mais importantes grupos. Os Serranos, por exemplo, grupo mais bem sucedido da música regional gaúcha (DIAS, 2008, p. 43), regravou canções de Pedro Ortaça em duas ocasiões: Bailanta do Tibúrcio (No disco "Bandeira dos Fortes", de 1987) e Timbre de Galo (no disco "Os Serranos interpretam sucessos Gaúchos”). Já o grupo Os Nativos (do Oeste de Santa Catarina) cantam dois temas recolhidos por Noel Guarany: Na Baixada do Manduca e Chimarrita sem Fronteira, ambas presentes no disco "18 Grandes Sucessos", de 1991. Também regravaram Baile da Cola Atada, de Ortaça, no disco "Canta Catrina" 1997. Por sua vez, a dupla de interpretes Oswaldir \& Carlos Magrão, regravou os quatro "troncos missioneiros": De Ortaça, Surungo no campo fundo, no disco "Versos, Guitarra e Caminho", de 1989, e Velha Gaita, no disco de mesmo nome, em 1993. Também do disco Velha Gaita, há uma gravação da canção "Canto dos Livres", de Cenair Maicá. Homem Rural, também de Cenair, está no disco Gaúcho "Amigo" de 2003. "Prece", poesia de Jaime Caetano Braun, está no disco "Querência Amada”, de 1997, enquanto Destino de Peão, de Noel Guarany, está no disco "China Atrevida", de 2004.

\section{Algumas considerações}

Além de fomentar uma Música (Regional) Missioneira, o principal legado dos artistas relacionados como Troncos Missioneiros está no pioneirismo da construção de uma identidade missioneira através da música. Como pontua a "música é, portanto, um meio pelo qual identidades são (des)construídas" (KONG, pág. 153 e 154) e como Castro ( 2009, p. 15) complementa "[evidencia] a importância dessa arte na formação de "comunidades imaginadas".

Como afirma Pommer (2009, pág. 163), ao analisar a produção da identidade missioneira na cidade de São Luiz Gonzaga, que desde fins dos anos 60 as obras de Jaime Caetano Braun e Noel Guarany "podem ser consideradas um dos pontos de partida na estruturação e na divulgação do que se acreditava ser a identidade missioneira". Além de ser um dos pontos de partida, para a autora a

\footnotetext{
${ }^{8}$ Irmão de Cenair Maicá, com inúmeros discos lançados.

${ }^{9}$ Filho de Cenair Maicá, gravou um CD.

${ }^{10}$ Interpreta as canções do seu pai, Noel Guarany.

${ }^{11}$ Natural de São Luiz Gonzaga, gravou o último disco de Noel Guarany: A volta do missioneiro.

${ }^{12}$ Onde o principal meio de difusão e consumo está nos festivais de canção nativa.

${ }^{13}$ Acordeonista nascido no interior de Santo Ângelo que trouxe para a Música Regional Missioneira elementos de sua formação formal em Música na UFSM.

${ }^{14}$ Cantor e compositor nascido em São Luiz Gonzaga, faz parte do grupo Buenas e M'Espalho. É sobrinho de Luiz Carlos Borges.

${ }^{15}$ Cantor e compositor nascido em São Luiz Gonzaga, faz parte do grupo Buenas e M'Espalho.

${ }^{16}$ Cantor e compositor nascido em São Luiz Gonzaga.

${ }^{17}$ Cantor e compositor, natural de São Miguel das Missões.
} 
Música Regional Missioneira (idem, pág. 178), “continua sendo um dos principais elementos de divulgação do que chamamos aqui de gaúcho missioneiro".

\section{Referências}

BRAUN, Jayme Caetano. Os Quatro Missioneiros. In: Troncos Missioneiros, faixa 1, 1987.

BRUM, Ceres Karan. Esta terra tem dono: uma análise antropológica de representações produzidas sobre o passado missioneiro no Rio Grande do Sul. Tese de doutorado em Antropologia Social PPGAS/UFRGS, 2005.

CASTRO, Daniel. Geografia e Música: a dupla face de uma relação. Revista Espaço e Cultura, UERJ, 2009.

DIAS, Valton Neves Chaves. 0 consumo de música regional como mediador de identidade. Dissertação, (Mestrado em Comunicação) Universidade Federal de Santa Maria, Santa Maria, 2008.

FAGUNDES, Nei. Jayme Caetano Braun: o grande payador. Porto Alegre: Martins Livreiro, 2010.

JÚDICE, Henrique. E a lança fez-se guitarra. Disponível e m < http: / / www.anovademocracia.com. br/no-53/2188-e-a-lanca-fez-se-guitarra> Acesso em 24 de abril de 2011 .

HOVES NETO, Guilherme. De bota e bombacha: um estudo antropológico sobre identidades gaúchas e o tradicionalismo. Dissertação, (Mestrado em Antropologia) Universidade Federal de Santa Maria, Santa Maria, 2009.

KONG, Lily. Música Popular nas análises geográficas. In: CORRÊA, R. L. \& ROSENDAHL, Z. (org.) Cinema, música e espaço. Rio de Janeiro: EdUERJ, 2009.

MANN, Henrique. Os Poetas. Som do sul - a história da

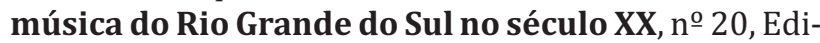
tora Tchê, $n \div$ 8, 2002a.
. Noel Guarany - Cenair Maicá. Som do sul - a história da música do Rio Grande do Sul no século $X X$, no 20, Editora Tchê, 2002b.

MINISTÉRIO DA CULTURA. Homologação do resultado final do prêmio culturas Populares 2008. Disponível em <http://www.cultura.gov.br/

site/wp-content/uploads/2008/11/homologacao-doresultado-final-premio-culturas-populares-2008.rtf> Acesso em 19 de abril de 2011.

OLIVEIRA, Silvio de; VERONA, Valdir. Gêneros musicais campeiros no Rio Grande do Sul: ensaio dirigido ao violão. Porto Alegre: ED. Nativismo, 2008.

ORTAÇA, Pedro. Pedro Ortaça - Release . Disponível em: <http://www.pedroortaca.com.br/?pg=8902. Acesso em 24 de abril de 2011.

PANITZ, Lucas. Por uma Geografia da Música: o espaço geográfico da Música Popular Platina. Dissertação de mestrado, PPGEA/UFRGS, 2010.

POMMER, Roselene Moreira Gomes. Missioneirismo história da produção de uma identidade regional. 1 . ed. Porto Alegre: Martins Livreiro, 2009.

PROSA GALPONEIRA. Lisandro Amaral canta Noel Guarany e Cenair Maicá. Disponível em: <http://prosagalponeira.blogspot.com/2009/11/lisan dro-amaral-canta-noel-guarany-e.html> Acesso em 19 de abril de 2011.

SILVEIRA, Flávio Leonel Abreu da. As paisagens fantásticas e o barroquismo das imagens: Estudo da memória coletiva de contadores de causo da região missioneira do Rio Grande do Sul. Tese de doutorado em Antropologia Social PPGAS/UFRGS, 2004.

SOSA, Chico. Noel Guarany, Destino Missioneiro. Santa Maria: Editora Che Sapucay, 2003. 


\title{
The Troncos Missioneiros and missioeira identity construction through music
}

\begin{abstract}
The music álbum named "Troncos Missioneiros" assembles four artists from Missões, a region of Rio Grande do Sul, Brazil: Jaime Caetano Braun, Noel Guarany, Cenair Maicá and Pedro Ortaça. Besides encouraging the regional music from Missões, these artists' main legacy is their pioneerism towards developing identity to the region through music. In what concerns regional identity, a few set of themes are emphasized: features of a rural past; the influence of the guarani culture; Latin America's existing border of integration/repulsion; Reductions Guaraníticas and its ruins. The development of the regional music from Missões begins based on major past influences, though is consolidated by the artists above. After them several artists born in that region identify themselves to the musical production from Missões, a lot of those are direct relatives from the "Troncos". In a bigger context, from the 90'on the regional music from Rio Grande do Sul develops itself in two paths: "Música Campeira" and "Tchê Music". There are remakes of Troncos Missioneiros' work made by both. Aiming to discuss this topic, we used as research methodology in sound archives at the Museu do Som Regional of the RS, located near the Instituo Gaúcho de Tradição e Folclore (IGTF) and also the collection of disks that we found on the internet. This paper subscribes to the New Cultural Geography through including new study subjects, in this case, popular music.
\end{abstract}

Keywords: Music \& Geography. Regional Music. Missões' Identity.

\section{Los Troncos Missioneisos y la construcción de la identidad misionera a través de la música}

Resumen: Troncos Missioneiros es el nombre de un disco que reúne a cuatro artistas de la región Misionera de Rio Grande do Sul: Jaime Caetano Braun, Noel Guarany, Cenair Maicá y Ortaca Pedro. Además de fomentar una canción Misionera Regional, el principal legado de los artistas relacionados como Troncos Missioneiros está en el pionerismo de la construcción de una identidad misionera a través de la música. En cuanto a la identidad regional, son enfatizados algunas temáticas principales: las características de un pasado rural, la frontera de integración latino-americana; las Reducciones Guaraníticas y sus ruinas. Ya la construcción de una Música Regional Misionera parte de algunas influencias anteriores importantes, pero es consolida por los artistas citados. Después de ellos, hay una amplia gama de artistas nacidos en la región que se identifican con la producción musical misionera, muchos de estos familiares directos de los Troncos. En un contexto más amplio, a partir de los años 90, la música regional de Rio Grande do Sul se desarrolla por dos caminos: Música Campera y la Tchê Music. En ambos, existen regrabaciones de la obra musical de los Troncos Missioneiros. Con el objetivo de discutir este tema, utilizamos como metodología la investigación en los archivos sonoros del Museu do Som Regional do RS, ubicado junto al Instituto Gaúcho de Tradicão e Folclore (IGTF) y también del acervo de discos que encontramos en la Internet. Nuestro trabajo vinculase a una Geografía Cultural Renovada, a partir de la inclusión de nuevos objetos de estudio, en nuestro caso, la música.

Palabras-clave: Música y Geografía. Música Regional. Identidad Misionera. 